\section{Public Health Review - International Journal of Public Health Research}

\title{
A prospective study on the clinical profile and outcome of patients with hyponatremia in a tertiary care centre in Kerala, South India
}

\author{
Grace N C M. ${ }^{1 *}$, Jacob K J. ${ }^{2}$, Rajesh K R. ${ }^{3}$, Vijayan S. ${ }^{4}$, Jayakrishnan C. ${ }^{5}$, Fatima ${ }^{6}$, Mathini S. ${ }^{7}$ \\ DOI: https://doi.org/10.17511/ijphr.2016.i2.05
}

1* Mary Grace N C, Associate Professor, Department of Medicine, Government Medical College, Thrissur, Kerala, India.

2 Jacob K J, Additional Professor, Government Medical College, Thrissur, Kerala, India.

3 Rajesh K R, Assistant Professor, Government Medical College, Thrissur, Kerala, India.

${ }^{4}$ Sarang Vijayan, Senior Resident, Department of Medicine, Government Medical College, Thrissur, Kerala, India.

$\mathbf{5}$ Jayakrishnan C, Junior Resident, Department of Medicine, Government Medical College, Thrissur, Kerala, India.

6 Fatima, Junior Resident, Department of Community Medicine, Government Medical College, Thrissur, Kerala, India.

7 Mathini S, Senior Resident, Department of Medicine, Government Medical College, Thrissur, Kerala, India.

Background: Hyponatremia is the commonest electrolyte disturbance seen in hospitalized patients. The presence of hyponatremia worsens the prognosis in ill patients. Aims: To study the clinical profile and outcome of patients having hypoosmolal hyponatremia. Methods: We studied a total of 100 consecutive patients, with serum sodium concentration less than $135 \mathrm{meq} / \mathrm{l}$. The study was conducted in a tertiary care centre in Kerala, South India. Those patients with hyponatremia who had normal or high serum osmolality were excluded from the study. Results: There were 55 (55\%) male patients and $45(44 \%)$ female patients. The ages ranged from 18 years to 88 years, with a mean age of $60+/-16$ years. The most common precipitating factor was neurological and lung conditions. Majority of the patients were asymptomatic at the time of detecting hyponatremia. Majority of the patients were euvolemic at the time of detection of hyponatremia. Conclusion: The conclusion we have drawn from this study is that euvolemic hyponatremia with urine sodium wasting is a more common cause for hyponatremia than conditions leading to hypovolemia. Since majority of the cases are asymptomatic, estimation of the serum electrolytes should be done as a routine in all hospitalized patients. Early recognition of hyponatremia and appropriate intervention would go a long way in improving the outcome.

Keywords: Hyponatremia, Euvolemic hyponatremia, Syndrome of inappropriate antidiuresis, Free water clearance

Corresponding Author

Mary Grace N C, Associate Professor, Department of Medicine, Government Medical College, Thrissur, Kerala, India.

Email: nc.grace@yahoo.in
How to Cite this Article

Mary Grace N C, Jacob K J, Rajesh K R, Vijayan S, Jayakrishnan C, Fatima, Mathini S. A prospective study on the clinical profile and outcome of patients with hyponatremia in a tertiary care centre in Kerala, South India. Public Health Rev Int J Public Health Res. 2016;3(2):70-74. Available From https://publichealth.medresearch.in/index.php/ijphr/ article/view/34

$\begin{array}{cc}\begin{array}{c}\text { Manuscript Received } \\ 2016-03-22\end{array} & \begin{array}{c}\text { Review Round } \mathbf{1} \\ 2016-04-02\end{array} \\ \begin{array}{c}\text { Conflict of Interest } \\ \text { No }\end{array} & \begin{array}{c}\text { Funding } \\ \text { Nil }\end{array}\end{array}$

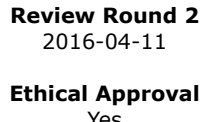
Attribution 4.0 International License https://creativecommons.org/licenses/by/4.0/ unported [CC BY 4.0]

To Browse

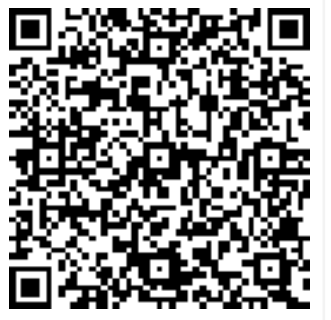

Note 


\section{Introduction}

The human osmoregulatory mechanisms functions in such a way that the normal sodium concentration ranges between $135 \mathrm{mmol} / \mathrm{l}$ to $142 \mathrm{mmol} / \mathrm{l}$. Serum sodium concentrations outside these ranges subjects the cells to hypotonic and hypertonic stresses and its consequences. Hyponatremia is defined as serum sodium concentration less than $135 \mathrm{meq} / \mathrm{l}$. It is the commonest electrolyte disturbance seen in hospitalized patients [1].

The presence of hyponatremia worsens the prognosis in ill patients. The spectrum of diseases in which hyponatremia was found to be an adverse prognostic factor was wide including conditions like myocardial infarction, cardiac failure,cirrhosis, pulomary infections. Mild hyponatremia has traditionally been considered to be an symptomatic condition. Recent evidence favours mild chronic hyponatremia to be the causative factor for ataxia, frequent falls and bone loss in elderly persons [2].

Hyponatremia related risk of mortality showed a reciprocal relationship with serum sodium levels [3]. There are also many problems faced by the physicians during the treatment of hyponatremia, like inadvertent over correction and osmotic demyelination syndrome. This is in addition to the problems caused by acute severe hyponatremia. Another important aspect in the management is to distinguish between euvolemic and hypovolemic hyponatremia clinically.

Considering all these factors, it is no wonder that many physicians feel that they are caught between the devil and the deep sea when they encounter hyponatremia in their patients. We conducted a prospective study on the clinical profile of hyponatremia in a tertiary care centre in South India.

\section{Aim}

To study the clinical profile and outcome of patients having hypoosmolal hyponatremia.

\section{Materials and Methods}

\section{Study design: Prospective study}

We studied a total of 100 consecutive patients, admitted in one medicine unit over a period of one year, with serum sodium concentration less than $135 \mathrm{meq} / \mathrm{l}$. Patients above the age of 18 years were included in the study.
The study was conducted in Government Medical College Thrissur which is a tertiary care centre in Kerala, South India. Those patients with hyponatremia who had normal or high serum osmolality were excluded from the study. Those with very high blood sugar levels, hyperlipidemia, and paraproteinemia and on mannitol were excluded.

The clinical data, including the mode of presentation, co morbidities, clinical features, laboratory investigations, treatment given and the outcome, were recorded .Volume status was assessed by clinical examination and supplemented by laboratory investigations and therapeutic interventions. Laboratory investigations included hemogram, blood sugar, renal and liver function tests, uric acid.

Thyroid function tests, serum cortisol estimations were done only in selected cases .Serum sodium was estimated using ion sensitive electrodes. Hyponatremia was defined as serum sodium less than $135 \mathrm{meq} / \mathrm{L}$. Serum sodium less than 120meq/I was taken as severe hyponatremia. Serum osmolality was calculated by the formula $2 \times(\mathrm{S} \mathrm{Na}$ $+\mathrm{K})+\mathrm{RBS} / 18+\mathrm{BUN} / 2.8$.

Urine osmolality, urine sodium, urine potassium was estimated in 84 cases. Urine was considered to be concentrated if the osmolality was more than 100 mosmol/I.Urine sodium excretion was considered to be high if it was $>20 \mathrm{meq} /$ l.Urinary free water clearance was estimated using the ratio urine sodium +urine potassium/serum sodium.

Statistical analysis was done using SPSS software. Chi- square test was used to find out the significance of difference between two proportions. A $p$ value less than .05 was taken as statistically significant.

\section{Results}

Demographics: There were 55 (55\%) male patients and 45 (44\%) female patients.

Table 1 : Distribution of patients

\begin{tabular}{|l|l|l|}
\hline \multicolumn{1}{|c|}{ Age group } & \multicolumn{1}{|c|}{ Number $(\mathbf{n})$} & \multicolumn{1}{c|}{ Percentage $(\%)$} \\
\hline $18-44$ years & 15 & 15 \\
\hline $45-64$ years & 37 & 37 \\
\hline $65-74$ years & 23 & 23 \\
\hline $75-84$ years & 24 & 24 \\
\hline$>85$ years & 1 & 1 \\
\hline
\end{tabular}

Age distribution: The ages ranged from 18 years to 88 years, with a mean age of $60+/-16$ years. 
The maximum number of patients belonged to the age group of 45 years to 64 years.

Table 2: Precipitating factors for hyponatremia

\begin{tabular}{|l|l|l|}
\hline \multicolumn{1}{|c|}{ Precipitating factors } & Number(n) & Percentage (\%) \\
\hline Vomiting and Diarrhea & 16 & 16 \\
\hline Lung diseases & 22 & 22 \\
\hline Neurological causes & 26 & 26 \\
\hline Malignancy & 2 & 2 \\
\hline Ascites, Renal failure & 17 & 17 \\
\hline Diuretics & 12 & 12 \\
\hline No obvious cause & 4 & 4 \\
\hline
\end{tabular}

Mode of presentation: Majority of the patients (52\%) were asymptomatic at the time of detecting hyponatremia. Among those who presented with symptoms altered level of consciousness was the most common mode of presentation (44\%). The other ways of presentation seen in few patients were vertigo, ataxia, and seizures.

Correlation of symptoms to severity of hyponatremia: In the group with serum sodium > $120 \mathrm{meq} / \mathrm{l}$, of the 55 patients only 17 patients were symptomatic. As serum sodium fell less than $120 \mathrm{meq} / \mathrm{l}$, of the total 45 patients 31 patients presented with symptoms ( $p$ value .000).

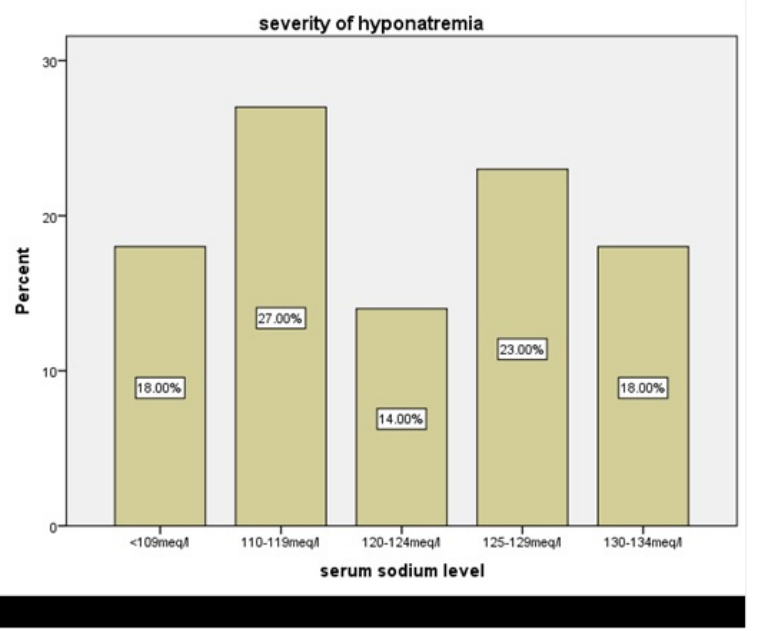

The mean sodium level was $119+/-10 \mathrm{meq} / \mathrm{l}$

Volume status: Majority of the patients were euvolemic $(82 \%)$ at the time of detection of hyponatremia. The least common group was the fluid overloaded status (8\%).

Urine sodium excretion: Urine sodium levels were estimated in 87 patients. Among these $82 \%$ of patients had urine sodium excretion more than 20 meq/l.21\% patients had urine sodium values between 20 and $40 \mathrm{meq} / \mathrm{l}$.
Of the 100 patients urine sodium excretion and urine osmolality was estimated in only 72 patients ,because of financial restraints. Among the 82 patients with euvolemic hyponatremia urine sodium excretion and urine osmolality was measured in 72 patients. In this euvolemic group only 3 (4.3\%) had urine osmolality less than $100 \mathrm{mosmol} / \mathrm{l}$.

Among the 72 euvolemic hyponatremic patients whom 52 patients (63.4\%) had urine sodium excretion $>40 \mathrm{meq} / \mathrm{l}$ while 16 patients (19.5\%) had urine sodium excretion between 20-40 meq/l. Of the total 68 patients with euvolemic hyponatremia and urine sodium loss more than 20meq/l, 54 (79.4\%) patients had serum creatinine value less than 1.5 $\mathrm{mg} \%$.

\section{Ratio of urine to serum electrolytes}

Among the 54 patients with laboratory results suggestive of SIAD, we estimated the ratio of urinary to serum electrolytes. 23 patients $(43.4 \%)$ had ratio more than 1 , while $17(32.1 \%)$ had ratio less than .5 and in 13 patients $(24.5 \%)$ the ratio was between .5-1

Comorbidities: Of the total 100 patients included in the study 61 patients had co morbidities like hypertension, diabetes, chronic obstructive airway disease, ischemic heart disease, cerebrovascular disease, malignancy.

Those who had co morbidities 32(52.5\%) had severe hyponatremia ( $<120 \mathrm{meq} / \mathrm{l})$. Among those without co morbidities only $13(33.3 \%)$ had severe hyponatremia (.p value .37)

\section{Discussion}

Hyponatremia is the commonest electrolyte disturbance seen in hospitalized patients. The incidence may be upto $30 \%$ especially in the critically ill patients [4]. Hyponatremia may be broadly classified based on the volume status into hypovolemic, euvolemic or hypervolemic hyponatremia. In all the true cases of hyponatremia the serum osmolality is below the normal.

The main pathogenic mechanism in hyponatremia is the increased ADH (antidiuretic hormone) secretion, which may be either appropriate (as in hypovolemic states either true hypovolemic or decrease in effective arterial blood volume) or inappropriate( as in syndrome of inappropriate antidiuresis SIAD).

The management of these different types of hyponatremia is different and the correct 
Identification of the type of hyponatremia is an integral part of the management. Clinical assessment as well as proper use of laboratory tests can help the physician to arrive at the correct diagnosis [5]. We did this prospective study to gain insight into the types of hyponatremia which is common in our centre and also the outcome of these patients.

Demographics: The maximum number of patients were in the age group of 45-64 years, followed by the age group $>75$ years. This was a surprising finding because it is well known that hyponatremia is a common electrolyte disorder among the elderly more than in younger subjects [6]. As in previous studies there is no sex predilection for the occurrence of hyponatremia [7].

Precipitating factors: In this study the most common precipitating cause for hyponatremia was nervous system abnormalities like cerebrovascular disease (both initial presentation of stroke as well as previous multiinfarct states). This was followed by lung diseases like pneumonia and lower respiratory tract infections in people with chronic obstructive airway diseases. These clinical entities are usually associated with inappropriate ADH secretion .This group was followed by causes like diarrhea, vomiting and use of diuretics. Fluid overloaded states due to ascites and chronic kidney disease was the least frequent group.

Mode of presentation: Majority of the patients were asymptomatic even with sodium levels less than $125 \mathrm{meq} / \mathrm{l}$. Chronic hyponatremia is generally believed to be free of symptoms with serum sodium upto $125 \mathrm{meq} / \mathrm{l}$ [8]. But it has been shown that subtle neurological abnormalities like frequent falls and gait disturbance may be due to mild hyponatremia [2]. Those who were symptomatic presented with altered level of consciousness, even among those whose precipitating cause was lung diseases and not neurological insults. In previous studies also this is the commonest mode of presentation [9].

Severity: The mean sodium level was much lower and the number of patients with severe hyponatremia was much higher in our study when compared to a similar study from Eastern India [10]. The incidence of severe hyponatremia from western studies is also much lower than what has been observed by us [1]. An association between poor nutrition and hyponatremia has been observed [6].
Volume status: Majority of patients in this study group were euvolemic (82\%).Hypovolemic hyponatremia has been found to be the commonest type in some studies [6]. In a study conducted in a tertiary care centre in the Eastern part of India, euvolemic hyponatremia accounted for $50.74 \%$

According to Rao MY et al SIADH is the commonest cause of hyponatremia among elderly patients followed by use of diuretics [11]. We observed only few cases of diuretic induced hyponatremia (12 patients ), probably because this study group had only fewer number (35 patients, ) of patients with hypertension. Majority of patients with euvolemic hyponatremia had concentrated urine (urine osmolality >100mosmol/l). Only 3 patients had dilute urine with osmolality $<100 \mathrm{mosmol} / \mathrm{l}$.

In the category of 64 patients with euvolemic hyponatremia with concentrated urine and urine sodium wasting $>20 \mathrm{meq} / \mathrm{l}$, 13 had serum creatinine $>1.5 \mathrm{mg} \%$. We did serum cortisol estimation in only selected cases. Even though the criteria for SIADH cannot be strictly applied we assume that the most common cause for euvolemic hyponatremia in this study group is syndrome of inappropriate antidiuresis (SIAD).

The chief causes for the syndrome of inappropriate antidiuresis were neurological conditions like cerebrovascular disease and respiratory infections including tuberculosis. This finding is similar to the observation made by Rao MY et al [11].

Treatment: Those patients with evidence of fluid loss were treated with replacement with normal saline, while those with euvolemic hyponatremia treatment were based on excretion of free water. $3 \%$ saline was given in only those severe cases which did not respond to fluid restriction.

The estimation of free water excretion helped us in determining the amount of fluid to be restricted in the category of patients with euvolemia [12]. In this study there is considerable number of patients in whom the ratio of urinary electrolyte of serum sodium is more than 1 . Thus it points the importance of estimating the urine potassium also in management of hyponatremia. There were no deaths among the patients in this study group.

Drawbacks: The chief drawbacks of this study are the limited sample size, lack of urine sodium, urine osmolality in all cases, failure to do serum cortisol estimation in all cases of euvolemic hyponatremia. 


\section{Conclusion}

The conclusion we have drawn from this study is that euvolemic hyponatremia with urine sodium wasting is a more common cause for hyponatremia than conditions leading to hypovolemia. Hence in the management; fluid restriction plays a very important role. Since majority of the cases are asymptomatic, estimation of the serum electrolytes should be done as a routine in all hospitalized patients.

Early recognition of hyponatremia and appropriate intervention would go a long way in improving the outcome. In the management the importance of determining the free water excretion has to be emphasized. The role of nutrition status in contributing to the occurrence of hyponatremia has to be studied further, especially in our country.

\section{Reference}

01. Funk GC, Lindner G, Druml W, Metnitz B, Swarz $C$, Bauer $\mathrm{P}$, et al. Incidence and prognosis of dysnatremias present on ICU admission. Intensive Care Med. 2010;36;304-11.

doi: 10.1007/s00134-009-1692-0. Epub 2009 Oct 22 [Crossref]

02. Renneboog B, Musch W, Vandemergel X, Manto MU, Decaux G. (2006) Mild chronic hyponatremia is associated with falls, unsteadiness and attention deficits. Am J Med. 2005; 119; 71;e1-8.

doi: 10.1016/j.amjmed.2005.09.026 [Crossref]

03. Corona G, Giuliani C, Parenti G, et al. Moderate hyponatremia is associated with increased risk of mortality- evidence from a meta-analysis. PLoS One. 2013;8(12)e80451 doi: 10.

1371/journal.pone.0080451 [Crossref]

04. Upadhyay A, Jaber BL, Madias NE. Incidence and prevalence of hyponatremia. Am J Med. 2006;119(Suppl 1)S30-5DOI.

http://dx.doi.org/10.1016/j.amjmed.2006.05.005 [Crossref]

05. Sahay M. Rakesh Sahay Hyponatremia-A practical approach. Indian J Endocrinol Meta. 2014; 18(6)760-771.

DOI: $\quad 10.4103 / 2230-8210.141320$ [Crossref]
06. Taipei Liang-Kung Chen, Ming-Hsien Lin, ShinnJang Hwang, Tzen-Wen Chen. Hyponatremia Among the Institutionalized Elderly in 2 LongTerm Care Facilities. J Chin Med Assoc. 2006;69(3)115-119 doi: 10 . 1016/S1726-4901(09)70188-1 [Crossref]

07. Al-Salman J, Kemp D, Randall D. Hyponatremia. West J Med. 2002 May;176(3)173-176.

[Crossref]

08. Janicic N, Verbalis JG. Evaluation and management of hypo-osmolality in hospitalized patients. Endocrinol Metab Clin North Am. $2003 ; 32 ; 459-481$.

DOI: [Article] [Crossref]

09. Paniker GI, Joseph S A. Prospective study on clinical profile of hyponatremia in ICU hospitalized patients. International Journal of Biomedical And Advance Research. 2014;5(6)297-303.

[Crossref]

10. Chatterjee N, Sengupta N, Das C, Chowdhuri AR, Basu AK, Pal SK. A descriptive study of hyponatremia in a tertiary care hospital of Eastern India. Indian J Endocrinol Metab. 2012; 16(2)288-291.

doi: $10.4103 / 2230-8210.93757$ [Crossref]

11. Rao MY, Sudhir U, Anil Kumar T, Saravanan S, Mahesh E, Punith K. Hospital-based descriptive study of symptomatic hyponatremia in elderly patients. J Assoc Physicians India. 2010;58;667-9.

[Crossref]

12. Laville M, Burst V, Peri A, Joseph G. Verbalis Hyponatremia secondary to the syndrome of inappropriate secretion of antidiuretic hormone (SIADH)- therapeutic decision-making in reallife cases. Clin Kidney J. 2013;6(1)i1-i20. doi: $10.1093 / \mathrm{ckj} / \mathrm{sft} 113$ [Crossref] 